\title{
Aikuiskasvatuksen tutkimus- ja kehittämistoiminnan näkymiä Suomessa ja muissa Pohjoismaissa
}

\begin{abstract}
Pantzar, Eero. 1983. Aikuiskasvatuksen tutkimus- ja kehittämistoiminnan näkymiä Suomessa ja muissa Pohjoismaissa. Aikuiskasvatus 3, 3, 118-121. - Artikkelissa tarkastellaan aikuiskasvatuksen tutkimus- ja kehittämistoiminnan tilaa ja sisältöä Suomessa ja muissa Pohjoismaissa. Vuonna 1982 kerättyyn pohjoismaiseen kartoitusaineistoon perustuva tutkimus, joka on artikkelin perustana, osoittaa tutkimus- ja kehittämistoiminnan sisällön pääpiirteissään eri Pohjoismaissa keskenään samanlaiseksi. Maiden yhteiskunta- ja aikuiskoulutusjärjestelmien samankaltaisuus lienee ohjannut myös tutkimus- ja kehittämismielenkiintoa samoihin teemoihin. Huomattavimmat tutkimus- ja kehittämistoimintaan liittyvät erot näkyvät puitteissa ja resursseissa. Suomalaista tutkimusta tehdään selvästi kehnoimmin resurssein. Kuitenkaan se ei näytä puuduttaneen tutkimusta ja kehittämispyrkimyksiä eikä latistaneen tasoa muiden pohjoismaiden tason alapuolelle. Alkaneella vuosikymmenellä ei kuitenkaan enää kyetä vastaamaan eteentuleviin haasteisiin nyk isissä puitteissa ja olemassa olevin resurssein.
\end{abstract}

Uusimpien tutkimustulosten osoittama jatkuvasti lisääntynyt osallistuminen aikuiskoulutukseen näyttää osaltaan myös vilkastuttaneen tutkimus- ja kehittämistoimintaa aikuiskasvatuksen alueella. (Tilastokeskus 1983).

Aikuiskoulutuksen tutkimus- ja kehittämistoiminnan merkitys eri Pohjoismaissa on aikojen kuluessa ollut varsin vaihteleva. (Aikuiskasvatus Pohjoismaissa 1976; Voksenundervisningen i Norden 1982). Merkityksen vaihtelun lisäksi tutkimus- ja kehittämistoiminnan muodoissa on havaittavissa eroja. (OECD 1980, 12). Pääasiallisesti 1960-luvulla alkanut, aluksi aikuiskasvatusjärjestelmien osa-alueita koskenut kehittämistoiminta ja tutkimustyö voimistuivat useimmissa Pohjoismaissa 1970luvulla. Kokonaisvaltaisen kehittämistoiminnan voimakas kausi on ollut 1970-luvun alun jälkeinen aika. (OECD 1980, 103-108; OECD 1982, 119; OECD/CERI 1972a, 21).

Yhteispohjoisimainen kiinnostus aikuiskasvatustutkimukseen heräsi 1960-luvun lopulla. Tällöin asetettu pohjoismainen asiantuntijatyöryhmä (Nordisk ekspertutvalg for forskning på voksenopplaeringens område) pyrki kartoittamaan tuohonastista tutkimus- ja kehittämistyötä. (Kruse et al. 1978, 18). Riittämättömien resurssien vuoksi jäi kattava kartoitus työryhmältä tekemättä. Raportti työn tuloksena kuitenkin syntyi (Eliasson et al.
1969. Rapport fra Nordisk ekspertutvalg for forskning på voksenopplaeringens område. Oslo.).

Raportissa käsiteltiin tutkimustehtäviä, pohjoismaista yhteistyötä, tutkijakoulutusta ja esimerkein eri maissa suoritettua tutkimusja kehittämistoimintaa. (Kruse et al. mt., 18).

Tutkimuksen ja kehittämistoiminnan vilkastuminen 1970-luvulla pani vauhtia ajatukseen aikaan saadun työn kartoittamisesta. Ajatus toteutettiin v. 1976, jolloin Pohjoismaiden ministerineuvoston kulttuuriyhteistyön sihteeristö toimeenpani kattavan selvitystyön. Sen tuloksena julkaistussa raportissa (Nye veier i voksenopplaeringen, NU B 1977: 41) on perustiedot eri Pohjoismaissa vv. 1970-77 suoritetuista tutkimus- ja kehittämisprojekteista. Tehtyä kartoitustyötä pidettiin niin tarkoituksenmukaisena, että uusi kartoitus - jatkoksi ja täydennykseksi aiemmalle - käynistyi v. 1981. Tämän kartoituksen raportin on määrä valmistua syksyllä 1983. Kartoitusaineisto on kerätty kansallisesti. Suomen osuudesta on vastannut Tampereen yliopiston aikuis- ja nuorikasvatuksen laitos. Kaikkiaan pohjoismaiseen kartoitukseen saatiin kootuksi 350 projektia.

Selkeämmän kuvan luomiseksi Pohjoismaiden aikuiskasvatustutkimuksesta ja aikuiskasvatukseen liittyvästä kehittämistoiminnasta on 
koottu dokumenttimateriaalia käytetty aineistona vertailevassa tutkimuksessa, jolla on pyritty erityisesti suomalaisen tutkimus- ja kehittämistoiminnan luonteen, sisällön ja piirteiden vertailuun suhteessa muihin Pohjoismaihin sekä suomalaisen toiminnan 'sisäiseen' analyysiin. Tässä, kartoitusaineistoa analysoivassa tutkimuksessa on mukana 297 projektia. Suomen aineiston keruun yhteydessä sovelletuin, käsitteistöön liittyvin perustein on viitisenkymmentä muutoin kartoituksessa mukana olevaa projektia rajattu tutkimusaineiston ulkopuolelle.

\section{Pohjoismaisen tutkimuksen yleiskuva}

Tarkasteltaessa pohjoismaista aikuiskasvatustutkimusta ja kokeiluja aikuiskasvatustieteen osa-alueille kohdistuvana toimintana havaitaan aikuisdidaktiikan ja aikuiskasvatuksen sosiologian vahva asema. Muiden osa-alueiden osuus on varsin vähäinen. Esimerkiksi vertailevan aikuiskasvatuksen osa-alue, jonka tutkimukselle olisi Pohjoismaissa perusteet ja edellytykset, on muutaman projektin varassa. (vrt Alanen 1978, 26--32).

Aikuiskasvatusjärjestelmässä suurin kiinnostus kohdistuu yksittäisistä osa-alueista ammatilliseen aikuiskoulutukseen ja vapaaseen sivistystyöhön. Tyypillisempää kuitenkin on se, että projektien kohde on koko aikuiskasvatusjärjestelmä tai yhtä osa-aluetta laajempi kokonaisuus. (Vrt. taulukko 1.).

Taulukko 1. Aikuiskasvatuksen tutkimus- ja kehittämisprojektien aikuiskasvatustieteen osatieteisiin kohdistuminen Pohjoismaissa (\%)

\begin{tabular}{|c|c|c|c|c|c|}
\hline \multirow{2}{*}{$\begin{array}{l}\text { aikuiskasva- } \\
\text { tustieteen } \\
\text { osatiede }\end{array}$} & \multicolumn{5}{|c|}{ Pohjoismaa } \\
\hline & $\begin{array}{c}\text { Suo- } \\
\text { mi }\end{array}$ & $\begin{array}{l}\text { Nor- } \\
\text { ja }\end{array}$ & $\begin{array}{l}\text { Ruots- } \\
\text { si }\end{array}$ & $\begin{array}{c}\text { Tans- } \\
\text { ka }\end{array}$ & $\begin{array}{c}\text { Kaik- } \\
\text { ki }\end{array}$ \\
\hline ak.sosiologia & 43 & 37 & 49 & 41 & 43 \\
\hline ak.psykologia & 7 & 4 & 13 & 7 & 8 \\
\hline aik.didaktiikka & 38 & 55 & 33 & 45 & 42 \\
\hline muut osa-alueet & 12 & 4 & 5 & 7 & 7 \\
\hline $\begin{array}{c}\text { YHTEENSÄ } \\
\text { (N) }\end{array}$ & $\begin{array}{l}100 \\
(69)\end{array}$ & $\begin{array}{l}100 \\
(71)\end{array}$ & $\begin{array}{l}100 \\
(86)\end{array}$ & $\begin{array}{l}100 \\
(71)\end{array}$ & $\begin{array}{c}100 \\
(297)\end{array}$ \\
\hline
\end{tabular}

Aikuiskoulutusprosessin vaiheista tutkimusta ja kehittämistoimia on kohdistunut runsaimmin opetuksen käytännön järjestelyjen ja toteuttamisen vaiheeseen. (Vrt. taulukko 2.).
Taulukko 2. Aikuiskasvatuksen tutkimus- ja kehittämisprojektien aikuiskoultusprosessin eri vaiheisiin kohdistuminen Pohjoismaissa (\%)

\begin{tabular}{|c|c|c|c|c|c|}
\hline \multirow{2}{*}{$\begin{array}{l}\text { aikuiskoulutus- } \\
\text { prosessin } \\
\text { vaihe }\end{array}$} & \multicolumn{5}{|c|}{ Pohjoismaa } \\
\hline & $\begin{array}{c}\text { Suo- } \\
\text { mi }\end{array}$ & $\begin{array}{l}\text { Nor- } \\
\text { ja }\end{array}$ & $\begin{array}{l}\text { Ruot- } \\
\text { si }\end{array}$ & $\begin{array}{c}\text { Tans- } \\
\text { ka }\end{array}$ & $\underset{\mathrm{ki}}{\text { Kaik- }}$ \\
\hline $\begin{array}{l}\text { teoria } \\
\text { hallinto ja }\end{array}$ & 17 & 6 & 17 & 11 & 13 \\
\hline & 4 & 1 & 2 & - & 2 \\
\hline suunnittelu & 38 & 27 & 42 & 26 & 33 \\
\hline $\begin{array}{l}\text { osallistuminen } \\
\text { opetuksen } \\
\text { järjestely ja } \\
\text { toteuttaminen }\end{array}$ & 32 & 15 & 30 & 14 & 12 \\
\hline $\begin{array}{l}\text { YHTEENSÄ } \\
\text { (N) }\end{array}$ & $\begin{array}{l}100 \\
(69)\end{array}$ & $\begin{array}{l}100 \\
(71)\end{array}$ & $\begin{array}{l}100 \\
(86)\end{array}$ & $\begin{array}{l}100 \\
(71)\end{array}$ & $\begin{array}{c}100 \\
(297)\end{array}$ \\
\hline
\end{tabular}

Pohjoismaissa projektien toteuttaja on useimmin ollut korkeakoulu tai erillinen tutkimuslaitos. Myös aikuiskasvatuksen kenttä laitoksineen ja organisaatioineen on ollut varsin aktiivinen tutkija ja kehittäjä. Pohjoismaiden projekteista voidaan edelleen todeta niistä suuremman osan olleet kestoltaan yli 2-vuotisia. Projekteista tiedon keruun tapahtuessa oli kesken $44 \%$, ja kirjallisesti oli raportoitu $69 \%$ : sta projekteja.

Pohjoismaissa suoritettujen projektien luonnetta voidaan arvioida vertailemalla niitä asetettuihin tutkimuspoliittisiin painopisteohjelmiin. Yhteispohjoismaista painopisteasettelua ei varsinaisesti tosin ole suoritettu. Löytyneet viittaukset (Oksanen 1973 ja Kruse et al. 1979) mainitsevat vuoden 1969 asiantuntijatyöryhmän (ks. edeltä), joka määritteli joitakin tärkeimpiä (ks. Eliasson et al. 1966) aikuiskasvatukseen liittyviä tutkimustehtäviä. Nämä liittyivät seuraaviin teemoihin: osallistuminen, oppiaineksen välittyminen, aikuisopettaja, aikuiskasvatusjärjestelmä sekä tavoitteet ja opetuksen sisällön ja aineksen valinta.

Jo yli kymmenen vuotta sitten laadittu painopisteiden määrittely ei liene sinänsä enää kovin ajankohtainen. Voitaneen kuitenkin todeta didaktisen tutkimuksen yleensä sekä tulleen painotetuksi keskeisenä tutkimusalueena että tutkitun ja kokeillun suhteellisen aktiivisesti viime vuosina.

Vertailtaessa uusinta kokeilua ja tutkimusta aiemmin tehtyyn havaitaan, ettei pohjoismaisissa puitteissa ole tapahtunut n. 10 vuoden aikana merkittäviä muutoksia (Pantzar 1982, 33). 
Suomessa suoritettu tutkimus- ja kehittämistoiminta poikkeaa varsin vähän sisällöltään ja ulkoisilta piirteiltään (projektien kesto, raportointi jne.) pohjoismaisesta yleislinjasta. (ks. taulukot 1. ja 2.).

\section{Piirteitä suomalaisesta tutkimus- ja kehittämistyöstä}

Ensimmäinen huomiota kiinnittävä piirre suomalaisissa projekteissa on se, että kiinnostus eri teemoihin vaihtelee projektin vastuullisen toteuttajan mukaan. Erot ovat selviä tarkastellaanpa asiaa aikuiskasvatusjärjestelmän osa-alueisiin kohdistuvana kiinnostuksena (taulukko 3) tai koulutusprosessin eri vaiheisiin kohdistumisena. Selvimmin erilaiset painotukset näkyvät korkeakoulujen aktiivisuutena aikuiskasvatuksen teorian tutkimisessa ja kentän laitosten ja organisaatioiden kiinnostuksena kehittää ja tutkia erityisesti opetuksen organisointiin ja toteuttamiseen liittyviä asioita.

Taulukko 3. Suomalaisten tutkimus- ja kehittämisprojektien kohdistuminen aikuiskasvatusjärjestelmän osa-alueille projektin toteuttajan mukaan ( $\%)$

\begin{tabular}{|c|c|c|c|c|c|}
\hline \multirow[t]{2}{*}{ osa-alue } & \multicolumn{5}{|c|}{ toteuttaja } \\
\hline & $\begin{array}{l}\text { kor- } \\
\text { kea- } \\
\text { koulu }\end{array}$ & $\begin{array}{c}\text { aik.k. } \\
\text { lai- } \\
\text { tos }\end{array}$ & $\begin{array}{l}\text { koulu- } \\
\text { hallin- } \\
\text { to }\end{array}$ & muut & kaikki \\
\hline $\begin{array}{l}\text { vapaa sivistys- } \\
\text { työ } \\
\text { ammatillinen }\end{array}$ & 29 & 56 & 13 & 10 & 33 \\
\hline aik.koulutus & 18 & 15 & 13 & 40 & 19 \\
\hline alueet & 18 & 18 & 7 & 10 & 15 \\
\hline monialueinen & 35 & 11 & 67 & 40 & 33 \\
\hline $\begin{array}{c}\text { YHTEENSÄ } \\
(\mathrm{N})\end{array}$ & $\begin{array}{l}100 \\
(17)\end{array}$ & $\begin{array}{l}100 \\
(27)\end{array}$ & $\begin{array}{l}100 \\
(15)\end{array}$ & $\begin{array}{l}100 \\
(10)\end{array}$ & $\begin{array}{c}100 \\
(69)\end{array}$ \\
\hline
\end{tabular}

Merkittävänä projektien toteuttajiin liittyvänä piirteenä on mainittava vielä koulutushallinnon - erityisesti alueellisen - aktiivisuus koulutussuunnittelua sivuavassa kehittämis- ja tutkimustoiminnassa. (Pantzar 1983)

Eri toteuttajien projektit eroavat toisistaan myös ulkoisilta piirteiltään. Korkeakouluissa suoritetut projektit ovat olleet pitkäkestoisimpia. Toisaalta niistä on raportoitu aktiivisim$\min$.

Suomalaisen tutkimus- ja kehittämistoiminnan kuva ei yleispohjoismaiseen tapaan ole muuttunut sisältönsä osalta 1970-luvun alusta näihin päiviin. Monet tärkeät teemat ovat edel- leenkin jääneet tutkimuksen ulkopuolelle, jopa aikuiskoulutuskomitean määrittämät (Kom.miet 1975) keskeiset tutkimus- ja kokeilutehtävät ovat osin käsittelemättä.

\section{Resurssien lisäys tarpeen Suomessa}

Aikuiskoulutuksen alueen tutkimus- ja kehittämistyön edellytykset ovat varsin erilaiset eri Pohjoismaissa. Kiistatta voidaan todeta Suomessa tutkimus- ja kehittämistyötä toteutettavan vähimmin resurssein. Näin voidaan sanoa huolimatta siitä, että esimerkiksi aikuiskoulutustutkimukseen ja kehittämiseen kohdistettuja resursseja on vaikea tarkoin mitata. Tässä yhteydessä käsitys eri Pohjoismaiden tilanteesta perustuu varsin heterogeeniseen aineistoon. (Voksenundervisningen i Norden 1982; Educational Research and Development at the NBE 1976; NFA 1982; Educational Research Policy 1974; Educational Research 1977; Anttlainen 1973).

Suomessa tilanteen heikkous näkyy selvästi koulutustutkimuksen taloudellisten resurssien sisäisessä jaossa. Kun Suomessa aikuiskoulutustutkimuksen menojen osuus on viime vuosina ollut n. $5 \%$ (Räty 1977) niin Ruotsissa liikutaan vastaavasti 18-19 \%:n tasolla. Tosin meillä on opetusministeriön, aina vuoteen 1986 saakka ulottuvissa suunnitelmissa kaavailtu em. osuuden kasvattamisesta jopa $10 \%$ :in (OpM 1982, 45). Voidaankin pitää erinomaisena saavutuksena sitä, että Suomessa on puutteista huolimatta pystytty pitämään tutkimus- ja kehittämistoiminta määrällisesti ja laadullisesti kilpailukykyisenä muiden Pohjoismaiden rinnalla.

Tutkimus- ja kehittämistoiminnan merkitys kasvaa tulevaisuudessa nopeasti koko aikuiskoulutuksen laajenemisen myötä.

Kuinka tämä tosiasia otetaan meillä huomioon, on vielä arvoitus.

Ilman selvää henkilö- ja talousresurssien lisäystä ei tutkimuksen eikä kehittämistoiminnan voi odottaa kehittyvän aikuiskoulutustoiminnan laajenemisen edellyttämällä tavalla. Lisäksi suomalainen aikuiskoulutustutkimuksen organisaatio vaatii selkiinnyttämistä ja tutkimustoiminta keskittämistä yksikköön, jolla on riittävät voimavarat. Syytä ei ole myöskään unohtaa tutkimus- ja kehittämistoiminnan perusedellytyksistä hallinnon, kentän ja tutkijoiden keskustelevaa ja ymmärtävää vuorovaikutusta. 


\section{Lähteet:}

Aikuiskoulutus Pohjoismaissa, 1976. NU 7:1976 Stockholm

Alanen A. 1978, Kansainvälinen vertailu aikuiskasvatuksen tutkimuksessa. Eurooppalainen aikuiskasvatus, Vapaan sivistystyön XXII vuosikirja. Ss 9-33. WSOY: Juva

Anttalainen M.-L. 1973, Selvitys aikuiskoulutusmenojen jakautumisesta eri rahoittajien kesken vuonna 1972. Julkaisematon.

Educational Research and Development at the NBE, 1976. The National Swedish Board of Education: Stockholm.

Educational Research in Europe, 1977. Unesco Institute for Education. Swets \& Zeitlinger: Amsterdam.

Educational Research Policy in European Coutries, 1974. Council of Europe: Strasbourg.

Eliasson T. ym. 1969, Rapport fra Nordisk ekspertutvalg for forskning på voksenopplaeringens område. Oslo.

Komiteanmietintö 1975: 28. Aikuiskoulutuskomitean II osamietintö. Helsinki.

Krause A. \& Holten-Andersen C. \& Paulsen S C 1979. Erfaringer fra kortlaegningen og formidling af 'Nye veier i voksenopplaeringen'. DPI: København.

NFA 1982. Nye veje i voksenundervisning og folkeoplysning. Nordisk konference om FoU-arbete. Helsingør 9-11.12.1981. Rapport 4:1982. Kungälv.
Nye veier i voksenopplaeringen, 1978. En kartleggning av forsknings- og utviklingsarbeide i Norden. NU B:41. København.

OECD 1980, Reviews of National Policies for Education: Denmark. OECD: Paris

OECD 1982 Reviews of National Policies for Education: Finland. OECD: Paris.

OECD/CERI 1973, Recurrent Education. Policy and Development in OECD Countries: The Swedish View of Recurrent Education.

Oksanen A. 1973, Aikuiskasvatuksen tutkimisesta. Kasvatus 3, ss. 145-147.

OpM 1982. Opetusministeriön hallinonalan toimintaa tukevan tutkimuksen yleissuunnitelma. Opetusministeriö, korkeakoulu- ja tiedeosaston julkaisuja No 46. Helsinki.

Pantzar E. 1982, Forschungs- und Entwicklungstrends der Erwachsenenbildung in Finnland heute. In: Karl Ch. u.a., Tendenzen und Projekte internationaler Erwachsenenbildung. Universität Hannover, Lehrgebiet Eb./Ausserschulische Jugendb. Hannover.

Pantzar E. 1983, Alueellinen tutkimus- ja kehitystyö tehokasta. Savon Sanomat, 24.6.1983.

Räty T. 1977, Valtion tutkimusmenot vuosina 197077. Suomen Akatemian julkaisuja 11. Helsinki.

Tilastokeskus 1983, Aikuiskoulutukseen osallistuminen 1980. Tilastokeskuksen tutkimuksia 92. Helsinki.

Voksenundervisningen i Norden, 1982. Nord: København. 